\title{
Discourse Control and Power ——Foucault's Discourse Control Principle
}

\author{
Dengjun Ye ${ }^{a}$, Liyong Tang ${ }^{b}$ \\ College of politics and law, Zhejiang Agriculture and Forestry University, Lin'an, Zhejiang 311300, \\ China \\ a1213191188@qq.com, b184097785@qq.com
}

Keywords: Foucault, Discourse control principle, power.

\begin{abstract}
Foucault's discourse include the following control principles: exclusive program of verbal taboo, the distinction between reason and madness and the truth will; Internal program of comment principle, the principle of the author, the discipline organization; The principle of the third group limited words - words ritual, the principle of discourse community, beliefs, social possession of the utterance. All of these are associated with power which limits the discourse. At the same time, the discourse also produced power to a certain extent. Giving a boost to Foucault's discourse control principle has important significance for us to understand the relationship between discourse and power.
\end{abstract}

\section{Introduction}

In Foucault's view, discourse is controlled, the controlled discourse form discourse order, discourse order reflects the role of power, and power constrained the human nature, so control discourse and power should be criticized to publicize the human nature. Visibly, discourse control status occupies fundamental in its theoretical basis. Its discourse control is: "in every society, the creation of discourse is controlled, chosen, organized and redistributed by a certain number program at the same time, its role are to eliminate the power and danger of discourse, control occasional events, avoid heavy and terrible materiality". Those programs reflect the role of power, power limits the discourse. And many people control others through language means, through the act of discourse, the latter determines the language, and restrict people to think about other possibilities. According to the related works, Foucault's discourse control principles can be summarized three groups and ten, this paper is mainly elaborated the principle, and expound their relation with the power.

\section{Discourse Control Principle - External Principle}

\subsection{Prohibitive languages}

People have no right to talk about all topics, some words can't be talked about in some situations, and not everyone has the right to speak casually. Here, we see three prohibitions: language object taboo - we can't say whatever arbitrarily, Language environment ritual - we can't talk about anything in favorite time and place; the power of the speech subject - we have no right to cannot say in a certain context. Ritual of speaking, occasion and identity constitute the restrictions of words, three prohibitions interact, strengthen or complement each other, form a complex network, the tightest is area of sex and politics: "discourse is one of the priority areas of sex and political power", "discourse are far from transparent or neutral environment, in which sex can be appeased and politic can be pacified, on the contrary, it is actually " the one areas that sex and politics exercise terrible power.

\subsection{The distinction of the craziness}

Crazy man's words are not freely circulated as other, it is regarded as invalid, not has credibility and importance, it can't as legal evidence, certification contract or contract. Strictly speaking, the crazy man's word "no" : "the modern people no longer talk with mad patients. On the other hand, a rational person entrusts the doctor to take care of the patient, it can be established relation only by the universality of abstract disease; on the other hand, mad patients only through the same abstract rational intermediaries, which is the social order, the social order constrain the body and moral, 
invisible pressure of social groups and requirements which conform, then it can communicate with society. As for the common language, it does not exist, or no these things no longer". The "crazy distinction"' is not a prohibition, but it is the difference and discrimination, namely "madness and civilization', which reveals the opposition between rationality and craziness.

\subsection{The will of truth}

This first embodied the so-called "truth" on so-called restrictions and exclusion of "falsehood". On the surface, the difference between truth and falsehood is not arbitrary, not can be corrected; neither system nor violence. "But when asked truth will through words was what before, what is it usually, generally what distinction control will to knowledge, but we can see the things similar to exclusive system, it depends on the systematic support: it is composed of various levels of practice including teaching method, book system, publications, library, academic community and laboratory, meanwhile, strengthen and update social application, mining, distribution, dividing knowledge way, which support the truth. It is closely related to social system, history, system and power in the history. Therefore, "the will to truth that depends on the system support and allocation will often exert constraint power on the other discourse". It will eventually exclude discourse which does not conform to systematic regulations.

\section{The Discourse Control Principle - Internal Procedures}

Besides the external restrictions, discourse control principles also have self-control and discourse itself. It is those procedures that act as discourse classification, sorting, the distribution of the principle, the purposes are to control the events and chance of discourse, and change the unpredictability of discourse. Obviously, this principle is associated with power.

\subsection{Principles of Review}

Level exists in discourse; there are discourse that make an indiscreet remark and discourse to be reviewed. The former is once discourse has said, it disappeared, no one remember. Nevertheless, the latter is the after discourse has been said, there will be many comments, but "' comments" only can do is said implied things in a text finally. What has been said should for the first time, must tirelessly repeated what have never said. Endless fluctuation of comment is by disguised repeated dream to internal aroused: in the visual field, perhaps it is only the start - purely from the book". Comments give the thing that discourse should have, it eliminate casual factor in a certain extent, it allows people to say the things outside the text, but should talk about the text itself as condition; it is the perfection of the text in some sense. Therefore, comments, repeated comments and have certain identity with the original text.

\subsection{The author's principle}

In addition to review principle, the author's principle is another principle that control discourse contingency; it complements the latter to a certain extent. But unlike the latter, it is limited the discourse of accidental factors by taking this individuality and self-identity function. It thinks that due to the existence of transcendental subject or psychological subjectivity these kinds of unite, continuous body to ensure simplification of statement type. If comments principle reflects the repeatability of discourse, so the author's principle embodies the role of identity. "The author's principle" is limited by "author" this title and character. As Nietzsche said "god is dead", Foucault said "people" is dead, so the left is only the "status" and "character" in the modern society, this is a kind of "destruction of subjectivity".

\subsection{Discipline organization}

Discipline organization is one principle of the controlling discourse generation; it limits the discourse by identity function of disciplinary boundaries. Its form is regular permanent restart: "subject form the control system of generating discourse, it inspires this kind of identity through eternity of this rules, fixed the boundary. It is the power of the discipline within a certain range, especially the "discourse power " of authority figure in discipline, it is so-called as "authoritative narrative". In ideology of discourse, the knowledge of discipline is not be regarded as a kind of understanding form, but is considered with the understanding equally. This is a monopoly of 
knowledge; it is a standardization power of the discourse in a kind of discipline. Habermas opposes this tendency, so puts forward the "social enlightenment" and "self-enlightenment" thought of "critical philosophy".

\section{The Principle of the Third Group Limited Discourse}

Exclusive program is that the external restrictions on discourse, internal procedure is the self-control of discourse itself, and the third group limited discourse principle is application conditions to determine discourse, and give certain specifications to the speaker. It is also that the power in the social norms and group norms paly a limited role in the discourse and subject.

\subsection{Discourse ritual}

Discourse ritual and "discourse taboo" is relevant in some aspects, for example, the "discourse of mad man" in some so-called formal "discourse place" is prohibited, or do not conform to the requirements of the discourse of ritual. It shows our discourse not only to meet certain grammatical rules, but also meet certain social rules. Although when we speak, not very clearly aware of them, but when we broke the rules, you may feel embarrassed and aware of their existence; it is a "negative principle". "Discourse ritual" is one of the performance of the "process of civilization", the so-called "civilization" means the power control through social discipline control and self-discipline to make the person's behavior (including language) in accordance with ritual. Power from violence to the ritual, it reflects in various "political techniques" and "power techniques", it turns out "tame body".

\subsection{Discourse community}

It makes the discourse in a closed space on the basis of strict rules to distribute. These discourses only exist in a group, also were only written, circulated, understood and spread in this group. For example, the author associations in published printed discourse field, there are various types of secret misappropriation and not-swap roles at work. Writing behavior, today has been in books, published system and the authors' role to be institutionalized, it is entirely possible happened in dispersed and restricted 'discourse community'. The difference between the author and other discourse and written main body, discourse of intransitive gives the fundamental uniqueness of " writing", and asymmetry exists in the 'creation and free use of language system, it show that the "existence of discourse community". According to different exclusive and exposure rules, and there are many other control means play a role, such as technology or scientific secrets, medical words spread and spread form, those who take up the political or economic discourse.

\subsection{Creed principle}

Creed principle and discourse community principle together link closely, sometimes a club is a community composed of true believers of one creed, of course, the former's range is more than the latter in many times. It makes the individual limited in a type of expression to ban other types of expression; but it is also, in turn, expressed in a certain type to connect individuals, and distinguish them and others. It is a double submission: discourse subject obey the discourse, and discourse are subject to individual group. This is a kind of spirit power, which makes the person loyal to a particular creed within the principle scope of the same creed; believe the discourse of the same creed, so as to ensure the invisible control of these people, build the identity of discourse main body, People is no value in front of the creed because have no choice. Creed discourse becomes a kind of "symbolic violence" which control and alienate people.

\subsection{Social possession of discourse}

Taking "Education" for example, education supposedly should be a kind of cultivated people's activity, everyone can by experience and contact with any discourse, but in fact the distribution and choice of the discourse is followed the route that the social distance, the opposition and struggle indicated. Every education system is to maintain or change the discourse possess and it's transferred knowledge and power political way: the people who is close to knowledge as control object, it is obvious that in education system that profession only hire members, it is a political way to maintain or revise discourse". 
In general, the above four principles has its generality: they are all control of the discourse application conditions, it is the control of the speaker type, it is the control discourse for circulation, exchange, communication (discourse practice), it make speaker distribute in different types of discourse, and those discourse types are diverted to some body type.

\section{Conclusion}

Foucault's discourse control principles are the above three groups and ten in general. Here, there are two problems worthy of discussion and analysis: Discourse control principle embodies the non-essentialism power analysis’ viewpoint, discourse and power connection, etc.

First of all, Foucault's "power" is not an entity, which is not in the hands of a person or a group, it is diffuse, and everywhere. Foucault is a "non-essentialism power analysis" man; it also can be seen in his "discourse control principle". First, the power is a kind of relationship. Taking review principle as an example, it is a relationship among repeated critics, critics, and author; it is also a relationship between review and original. Second, the power lies in implementation. "The distinction between rationality and crazy" are by make the generally madman into a mental hospital, the seriously madman, prisoners who violate taboos into jail, in "panoramic open view" way, they are disciplined and punished and so on to carry out power. Third, the power and resistance coexist. In internal and external "creed principle", there will be some existence of, without resisted discourse conflicting creed discourse; there are no real creed principles.

Secondly, what Foucault said "the truth will" is the Nietzsche's "the power will", he talked about truth will behind truth discourse in discourse control principle, and it has a certain perspective. They are not only the nature of desire, but also rely on the support of system. Truth will is associated with the power will; discourse are associated with power target: "the truth discourse by circulated relationship connected the power system, power effect to form "truth" kingdom, the discourse is no longer pure tool of express experience, and it becomes purpose itself", "the discourse not only change rule struggle or system, it is - struggle exists because of it, with the help of it, discourse is power to be competing". In bourgeois discourse, there is no truth, there is only one truth will and the power will. Discourse and "hegemony" Gramsci said, and "class consciousness" Lukacs said. Foucault in exposing the myth of eternal truths of capitalism that is consistent with Marx, he has Marx's criticism spirit.

\section{Acknowledgements}

[Fund Project] Humanities and social science research youth fund projects for Ministry of education (12YJCZH183).

\section{References}

[1] Foucault, M: The order of discourse. In M. Shapiro (Ed.), Language and Politics says, Oxford: Basil Blackwell, 1984.

[2] Foucault: "Madness and Civilization", Zhejiang People's Publishing House, 1998, "preface" 2.

[3] Foucault, M: The Archaeology of Knowledge, trans. A. M. Smith, Sheridan Pantheon Books, New York, 1972, p.219-224

[4] Habermas, J: Theorie und Praxis, Frankfurt am Main, 1993, p.228-289.

[5] Israel: "Dialectics of Language and Language of Dialectics", Commercial Press, 1990.

[6] Bourdieu, Kant, "Practice and Reflection," Central Compilation \& Translation Press, 1998, p. 186

[7] Mo Weimin: "The Fate of the Main Body, Foucault's philosophy research, Shanghai Sanlian Press, 1996, p.205-204 
[8] Foucault: "discipline and punishment", Sanlian Press, 1999), p. 219.

[9] Rabinow, P: The Foucault Reader. Hamondsworth: Penguin Books, 1984, p.74.

[10] Liu Beicheng: Portrait of Foucault’S Thought ", Shanghai People's Press, 2001, p.114. 